\title{
New insights, new challenges; person centred transport design
}

\author{
Andree Woodcock ${ }^{1}$ \\ Centre of Excellence in Product and Automotive Design, Department of Industrial Design, Coventry School of Art \\ and Design Coventry University, Coventry, $U K$
}

\begin{abstract}
This paper uses the Hexagon Spindle model of ergonomics to provide a framework for the development of person centred approaches to vehicle and transport design. The benefits of taking this approach, and the factors that might be included under a more inclusive definition of automotive and transport ergonomics are explained.
\end{abstract}

Keywords: Transport ergonomics

\section{Introduction}

Transport is at the heart of some of the most significant societal grand challenges. While advances in technology have simplified movement around the world, increased levels of commuting have impacted on economies, the environment and public health. It is estimated that transport problems cost the UK economy $£ 45 \mathrm{bn} / \mathrm{year}$ and the overdependence on personal, motorised forms of public transport are unsustainable and are fuelling ill health. Addressing these issues needs a multidisciplinary and holistic approach - one that places people at the heart of the solution, the creation of new high-quality, betterconnected living spaces, and the use of technology to improve the way we move goods and people.

Ergonomics seeks to maximise safety, efficiency and comfort through design which matches the operator's abilities. This paper addresses the factors which effect humans interaction with vehicles and the traffic environment. It is widely accepted that transport systems and vehicles have to be designed from a person centred perspective. The close relationship between the human and machine is apparent in many operations in transport, for example the way in which the car presents information about its per- formance to the driver (through auditory, tactile and visual displays), the design of controls which enable the driver to manipulate the vehicle through changing road conditions, the design and positioning of road signs to be quickly and easily comprehended. More recentlt attention has focused on the reverse direction as well, the effects the close relationship of man and transport has on the quality of life and the environment.

\section{The Hexagon Spindle model and its benefits}

With the spotlight on the need to improve the quality and efficiency of transport, inclusivity and the need to reduce carbon emissions and the rapid incorporation of technology supporting all interactions with transport, research in the field of transport ergonomics is increasing, This is exemplified at Coventry University by two Grand Challenge Initiatives in the fields of Low Carbon Vehicles and Integrated Transport and Logistics (IT\&L GCI)

The Integrated Transport and Logistics Grand Challenge (IT\&L GCI) maintains a person centred approach to its investigations, emphasizing the quality of the passenger or citizen's experience. As part

\footnotetext{
${ }^{1}$ Corresponding author: A.Woodcock@coventry.ac.uk
} 
of this, we are using the Hexagon Spindle Model of Ergonomics to provide the context for research activities. This section introduces the model before showing how it can be used to organize the diverse range of transport ergonomics research.

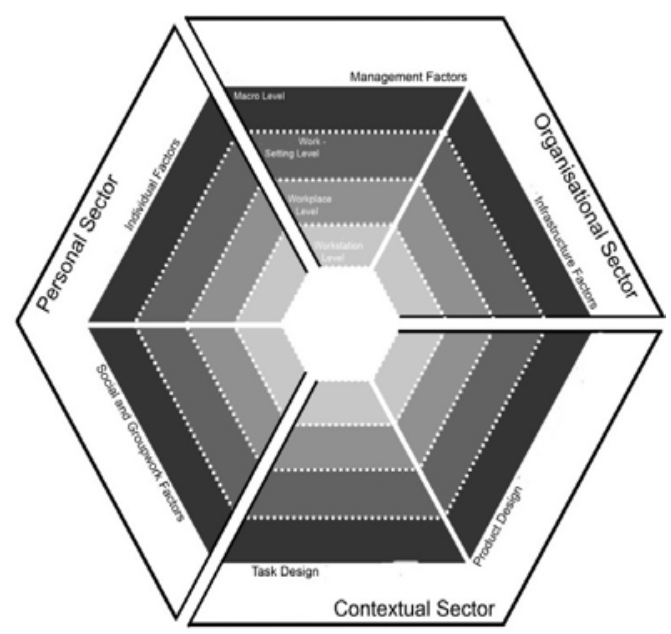

Figure 1: Hexagon Spindle model

[1] (page 10) emphasised: "Human-machine interaction does not take place in a vacuum...ergonomic techniques are needed to predict, investigate or develop each of the possible interactions, between person-task, person-process, person-environment, person-job, person-person, person-organisation and person-outside world."

This is recognized in the Hexagon Spindle (H-S) Model [2 and 3]. It provides a clear division of the factors which influence task completion, between the constant characteristics of the user and individual task dependent variables. Although the model was developed to elucidate the factors which effect task interactions in learning environments, its generic nature means that it can be applied to different domains.

The H-S Model stresses that different tasks take place in different settings, with different interactions - a person's day, or a journey can be broken down, with only some items remaining constant across time (such as fixed factors in the environment). In taking a person centred perspective to the design of transport systems this recognizes;

- the need to support a person's entire journey, not just the design of one particular aspect, or interaction. A commuter's journey may be composed of different elements. Therefore an effec- tive user centred transport system must support the entire, door-to-door journey.

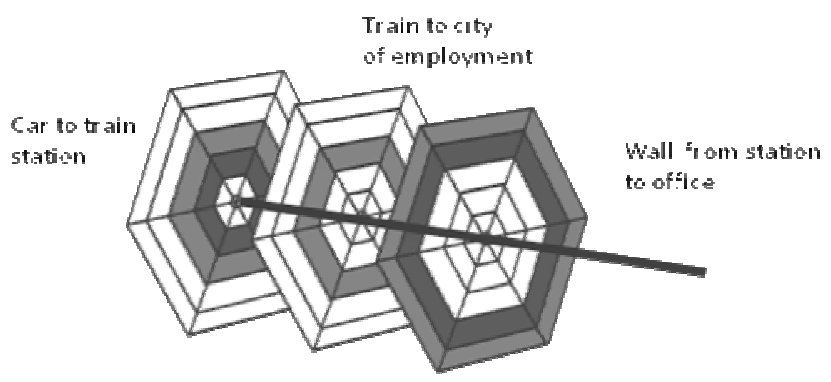

Shading denotes relative importance of factors for that stage of the journey

Figure 2: Stages of a commuter's journey

- The changing nature of human characteristics across the day and task. Tailorable systems, including transport ones, need to acknowledge and adapt to changes in human characteristics over time such as length of journey, motivation, reactions of other drivers. All of these have the potential to affect driving performance.

\section{Applying the H-S model to transport design}

\subsection{Users and their characteristics}

Taking the user as the starting point, it is possible to identify distinct user groups who have been the focus of attention in transport research. These can be primary and secondary users (drivers, passengers, pedestrians), of different vehicle types (terrestrial, marine, or airborne), having different characteristics (e.g. physical or cognitive) and/or driving under different situations (when tired, rushed, intoxicated, using a telephone etc). Any one of these might affect their interaction with the vehicle or the transport system. The following section will consider obese transport users.

Whilst vehicle designers have recognized the need to accommodate height variation, there has been a slower response to the global increase in weight and the accompanying increase in population girth. In the UK, $25 \%$ of the adult population are overweight, $22 \%$ of males and $21 \%$ of females are obese [4]. Although weight reduction initiatives are in place in many countries, the global trend is likely to increase, for example due to changes in diet, lifestyle, energy 
expenditure and the growth in obesogenic environments [5]. One such initiative that is gaining support in countries such as UK, China, Australia and US is active transport [6 and 7] where people are encouraged to adopt non motorized forms of transport (e.g., walking, cycling). This is an example of how a macro level user characteristic is influencing government and organizational policies and urban transport design (e.g. through the creation of bicycle lanes and incentives to adopt a more healthy lifestyle).

Table 1

Examples of problems for overweight bus drivers and the passengers

\begin{tabular}{|l|l|l|l|}
\hline $\begin{array}{l}\text { Level of } \\
\text { consideration }\end{array}$ & Definitions & $\begin{array}{l}\text { Overweight } \\
\text { bus driver }\end{array}$ & $\begin{array}{l}\text { Overweight } \\
\text { bus passenger }\end{array}$ \\
\hline Work station & $\begin{array}{l}\text { Immediate } \\
\text { task envi- } \\
\text { ronment }\end{array}$ & $\begin{array}{l}\text { Seat design, } \\
\text { reach for } \\
\text { primary and } \\
\text { secondary } \\
\text { controls; in- } \\
\text { crease in mus- } \\
\text { culoskeletal s } \\
\text { disorders }\end{array}$ & $\begin{array}{l}\text { Lack of space } \\
\text { to sit com- } \\
\text { fortably and } \\
\text { safely, seat } \\
\text { belts requiring } \\
\text { extensions }\end{array}$ \\
\hline Work place & $\begin{array}{l}\text { The wider } \\
\text { vehicular } \\
\text { environment }\end{array}$ & $\begin{array}{l}\text { Ingress and } \\
\text { egress into cab }\end{array}$ & $\begin{array}{l}\text { Narrow aisles } \\
\text { between seats }\end{array}$ \\
\hline Work setting & $\begin{array}{l}\text { The wider } \\
\text { environment } \\
\text { in which the } \\
\text { vehicle and } \\
\text { occupant are } \\
\text { contained }\end{array}$ & $\begin{array}{l}\text { Organisational } \\
\text { policy for } \\
\text { obese drivers; } \\
\text { provision of } \\
\text { healthy } \\
\text { food/exercise } \\
\text { breaks }\end{array}$ & $\begin{array}{l}\text { Long dis- } \\
\text { tances re- } \\
\text { quired to walk } \\
\text { in transport } \\
\text { gateways; } \\
\text { discriminatory } \\
\text { practices }\end{array}$ \\
\hline $\begin{array}{l}\text { Macro level } \\
\text { issues }\end{array}$ & $\begin{array}{l}\text { Wider issues } \\
\text { beyond } \\
\text { individual } \\
\text { control } \\
\text { current Dis- } \\
\text { ability Dis- } \\
\text { crimination } \\
\text { Act }\end{array}$ & $\begin{array}{l}\text { Active trans- } \\
\text { port schemes; }\end{array}$ & and \\
\hline
\end{tabular}

Currently, overweight and obese drivers and users of public transport may face uncomfortable, unsafe journeys and discriminatory practices. Table 1 identifies some of these issues, and is useful in establishing where change may be needed to improve vehicular and station design and organizational practice. This is because the design of vehicles and transport facilities may fail to recognize their needs in terms of seat design, crashworthiness and station layout. Larger passengers report feeling stigmatized when they are required to occupy two seats, with some economy airlines contemplating a fat tax [8]. Overweight drivers of public transport vehicles face health consequences [9] in part due to the design of their workstation and are subject to discriminatory practices (requiring them to lose weight if they wish to keep their jobs [10]. Recognition that the needs of a large percentage of the population are not being accommodated are also evidenced by the retrofitting of theme park rides [11] and ambulances [12].

The above example shows how the characteristics of one particular section of the population need to be considered if transport is to be inclusive, the barriers towards interaction removed, higher levels of satisfaction and efficiency achieved and how factors outside an individual's control might affect interaction.

\subsection{The personal sector}

The personal sector considers factors which may vary in relation to a specific task, from individual to individual.

\subsubsection{Individual factors}

[13] conducted a survey of stakeholder attitudes to electric park and ride buses in a small city in the UK. A member of the public's concern over ill health caused by traffic pollution and attitudes towards sustainability might increase their use of park and ride services, even though such services might not always be convenient. An overriding environmental concern, or an 'early adopter 'characteristic may also be a factor in the purchase of e-vehicles and lead to a greater tolerance of the current inconveniences and high price of such vehicles (e.g. in terms of charging points).

Other personal factors which need to be taken into account include social, psychological and physiological factors such as intelligence, motivation, attitudes, socio economic group, earnings, peer group, age and sensory, physical and cognitive abilities and the implications of these on all levels of activity from purchasing decisions, though to choice of transport and driving performance.

\subsubsection{Social and group factors}

Participation in transport is a social exercise. One might drive in isolation, but actions are influenced by other road users; both those within and outside of the vehicle. For example it has been noted that the driving of young drivers is influenced by the type of passengers being carried [14] and factors such as parental, community and cultural norms, demographic factors etc [15]. Driving style might differ with the behaviour of other motorists; for example in terms of speed [16], and lane changing, and in reaction to other aggressive drivers [17]. Therefore the interaction 
of individual and social factors has a mediating influence on the receptivity of individuals to vehicle information, performance capabilities and transport legislation.

The influence of social and group factors on driver behaviour is now being exploited by in-vehicle telematics applications targeting greener driving and speed reduction. The motivations for such work are the need to address global environmental issues, plus the congestion and pollution caused by cars. The realization that transport needs to change is driving government policy and car manufacturers to provide alternatively powered vehicles (such as electric and hybrid vehicles) and encourage drivers to behave in more environmentally responsive ways.

Sensor technology and related research enables vehicle performance to be captured and presented in ways that will lead to more environmentally friendly driving. Technological developments allow the performance of the driven car be fed back to the driver. The performance (e.g. in terms of feed and fuel efficiency) of others (e.g. friends, work colleagues, best and worst drivers) can also be presented, with the expectation that this will directly influence driver behaviour. This territory is just being explored, so although HMI principles relating to display characteristics can be applied to the new display designs, the receptivity of different individuals to this information is not yet known [18]. For example, will knowing that other drivers in my street drive more slowly than I do influence my preference for fast driving?

\subsection{Contextual sector}

\subsubsection{Task design factors}

The driving task can be divided into three classes, with associated devices as show in Table 1. More details are available [19 and 20].

Table 2

Driving tasks

\begin{tabular}{|l|l|l|l|}
\hline Task & $\begin{array}{l}\text { Example func- } \\
\text { tions }\end{array}$ & $\begin{array}{l}\text { Example } \\
\text { devices }\end{array}$ & $\begin{array}{l}\text { Design and } \\
\text { position }\end{array}$ \\
\hline Primary & $\begin{array}{l}\text { Maneuvering } \\
\text { the car, control- } \\
\text { ling speed, } \\
\text { checking dis- } \\
\text { tance to other } \\
\text { cars and objects }\end{array}$ & $\begin{array}{l}\text { Devices used } \\
\text { to maneuver } \\
\text { the car e.g. } \\
\text { steering wheel } \\
\text { and pedals }\end{array}$ & $\begin{array}{l}\text { Mapped one- } \\
\text { to-one with } \\
\text { their func- } \\
\text { tionality, } \\
\text { provide hap- } \\
\text { tic feedback. } \\
\text { Arranged } \\
\text { close to the }\end{array}$ \\
\hline
\end{tabular}

\begin{tabular}{|c|c|c|c|}
\hline & & & $\begin{array}{l}\text { driver so they } \\
\text { are in easy } \\
\text { reach }\end{array}$ \\
\hline Secondary & $\begin{array}{l}\text { Functions that } \\
\text { increase the } \\
\text { safety for the } \\
\text { driver, car and } \\
\text { environment } \\
\text { e.g. setting } \\
\text { turning signals } \\
\text { or activating } \\
\text { windshield } \\
\text { wipers }\end{array}$ & $\begin{array}{l}\text { Stalk controls } \\
\text { for turning } \\
\text { signals or } \\
\text { windscreen } \\
\text { wipers. }\end{array}$ & $\begin{array}{l}\text { In easy to } \\
\text { reach distance } \\
\text { and direct } \\
\text { field of view }\end{array}$ \\
\hline Tertiary & $\begin{array}{l}\text { Functions not } \\
\text { related primar- } \\
\text { ily to driving } \\
\text { such as enter- } \\
\text { tainment and } \\
\text { information } \\
\text { systems. }\end{array}$ & $\begin{array}{l}\text { Information } \\
\text { and enter- } \\
\text { tainment } \\
\text { systems }\end{array}$ & $\begin{array}{l}\text { Outside pri- } \\
\text { mary work- } \\
\text { space, but } \\
\text { within the } \\
\text { workspace } \\
\text { envelope } \\
\text { usually } \\
\text { mounted on } \\
\text { the centre } \\
\text { stack }\end{array}$ \\
\hline
\end{tabular}

Output devices provide feedback about the current state of the system. This can be delivered through visual, auditory of haptic channels. Obviously information of central importance to the driver is placed within the direct field of vision, in a way that attention does not have to be taken away from the primary driving task. International standards provide interaction design recommendation and enforcements (e.g. [21]), and design guidelines [22] describe how to make systems safe and easy to use for all drivers, e.g. through providing recommendations on text size, placement of displays taking into account safety and usability issues. An understanding of the driver's workspace is critical, as the driver is in a relatively fixed position. [23] provide a review of different input and output devices and their locations, using this to characterize the automotive design space.

To understand the position of these in relation to the driver, vehicle occupant packages are to ensure that adequate levels of accommodation, comfort and safety. The, occupant package, whilst focusing primarily on the driver, is also used to ensure the fit, ingress and egress of passengers. The package provides an accurate diagrammatic, 2 or $2 \mathrm{~d}$ representa- 
tion of the location and adjustment ranges of the steering wheel and seat with respect to the pedals, and the physical locations of all displays and controls that the driver interacts with. Diver vision is modeled with respect to interior and exterior sight lines to ensure the visibility of primary vehicle controls, views through mirrors and to the front of the vehicle. Accommodation should ensure that the largest percentage of the population can be suited in terms of fit, comfort and vision. This can be achieved through optimal placement of controls, mirrors and displays in relation to the occupants' positions and the degree of adjustability allowed in the design.

Therefore, designing a vehicle from the user's perspective requires knowledge of the driving task, physiological and psychological issues related to the driver and the ways in which these can be accommodated in the layout.

\subsubsection{Product design factors}

This sector deals specifically with the way in which the design of the product influences user interaction. The product in question could refer to a particular visual display through to the design of the vehicle or transport system. This is exemplified in [24]'s study of the redesign of a bus driver's workstation which illustrates how driver workstations can affect the health of drivers, how redesign can address these problems, how the views of representative end users can be fed into this process and the variety of methods that can be employed at different stages of the design process.

\subsection{Organisational sector}

\subsubsection{Infrastructure and the wider environment transport system}

Infrastructure relates to the network over which the vehicles operate and its related technology, through to the implementation of national rules and regulations governing flow and speed of transport and the design of the network as it affects drivers and passengers. Additionally the integration and interoperability of different transport services is now given attention with a new focus on the whole journey experience (whether for freight or passengers).

Previous research has considered issues such as road layout, markings and traffic rules and regulations. For example, [24] studied the effects of traffic light synchronization on the running of red lights. Synchronized intersections smooth the flow of traffic. This in turn reduces driver frustration from having to start and stop and intersection-related accidents, particularly rear-end collisions [26]. [27] looked at whether synchronization not only reduced the opportunities for intersection conflict, as vehicles travelled together in group, but also whether it changed driver behavior (i.e. reduced the inclination to run red lights). They found that when drivers were driving along a route with synchronized red lights they were less likely run the lights, and that this benefit was greatest when the traffic is light. They concluded that 'these findings demonstrate the importance of engineering and design in the alleviation of one type of aggressive driving....... It thus demonstrates a basic ergonomics principle: Changing the environment may be more effective than changing its users'.

Current research focuses on how knowledge of the transport situation may influence behaviour, from the level of what modes of transport to use, through to route choice and individual driver behaviour.

\subsubsection{Public transport}

The UK government is stressing the need to improve the quality of the passenger experience along the course of the whole journey to increase the use of public transport. Importantly in terms of infrastructure this highlights the need for joined up journeys, which do not require passengers struggling to locate services, providing services that enable passengers to select, book and monitor their services etc.

This 'macro level' push towards behaviour change has effects for travelers in terms of the level of service provided and their interaction with those services. A clear relationship is seen between improved service design and the uptake of that service. For example in terms of bus usage, changes to the quality and extent of services, the environment around bus stops, availability of information, ease and efficiency of ticketing arrangements, introduction of bus lanes, priority signaling, smart ticketing and enforcement of parking restrictions etc have contributed to significant increases in the use of bus services in many English counties [28].

Operating within this arena the role for ergonomists is twofold; 1) to understand the passenger experience, their needs, requirements and barriers to use of the system, present these issues to service providers, and evaluate the resultant changes (e.g. the usability of new ticketing processes, display of service information, accessibility of services and availability of information);2) to provide guidance on the design of tools and HMI which present transport in- 
formation in the right format, at the right time and in a form that can be acted upon by all members of the user population.

\subsubsection{Representation of information from the infrastructure and wider environment in vehicles}

Technological advances in the areas of primary and secondary safety represent a major challenge at all levels of the level of the transport network (see [29] for a review) in terms of their design, delivery and use.. There are several basic assumptions about providing more information to drivers; that they will want to know the information, attend to it, be able to act upon it.

In the more advanced integrated safety systems, the driver may be removed from the control loop, i.e. the car automatically receives advances notification of events and acts on that information. In integrated safety systems the vehicle can monitor the likelihood of a collision, use primary safety systems to avoid or reduce its severity, and alert the secondary systems to protect the occupant when the collision occurs. The concept of integrated safety has been enabled by the development of advanced sensors that can detect the current state of a vehicle and predict the likelihood of a collision occurring by monitoring the road environment.

\subsection{Managerial sector}

. For the transport user the 'work setting' may be interpreted as either 1) The organization in which the operator (driver, pilot or bus conductor for example) works, or 2) The wider environment in which the work takes place, e.g. the road transport network or rail system in which the vehicle is located. There is a need to recognize and understand the wider issues which might affect the behaviour of the traveler, or driver and accommodate these where possible through sensitive and tailorable design.

Operational and organizational issues (such as organizational ethos, culture and regulations) can effect the operators of public transport, and hence ethe safety and well being of not only the drivers but the passengers and other transport users as well.

[30] discussed the effects of organizational decisions on pilots in relation to efficiency and pilot workload . He argued that the operation of an airliner is not just about the pilot, the aircraft and the mission, but is also about the societal environment and the role of management. In terms of crew rostering [31] noted that changes to a rostering system re- duced operational risk, produced less fatiguing work patterns, improved productivity by $7 \%$, reduced insurance premium (by $£ 4$ million), improved crew lifestyle and pilot retention and decreased sickness and training.

[32] studied the occupational health and safety of Australian truck drivers as supply chain rationalization and government policies were producing an increasingly competitive industry, with relatively easy entry and intense price based bidding. This has encouraged cost saving employment practices - such as increased subcontracting, contingent work and pay systems (such as delivery time bonus/penalties and linking pay to distance travelled). In this case, government legislation (such as deregulation and the opening up of markets) produced changes to the work setting (or behavior of the organization) which controls the design of the driving task. Increased competition resulted in the need for work intensification and reduced labour costs. This has been achieved through (for example) increasing the size of the vehicles, using fleets more intensively, reducing driver payments, engaging self employed or cheaper drivers, or increasing the work load. [33] characterized 'trucking' as a 'sweated industry', where intense competition reduces pay to a point where the longest working hours provide a subsistence wage imperiling health and well being. In Europe, [34] argued that highly articulated transport systems adopting systems such as JIT were not conducive to safety.

\section{Summary}

This paper has shown how the H-S model can be used to organise transport related research whilst keeping the user in focus, The Integrated Transport and Logistics Grand Challenge Initiative at Coventry University focuses on the passenger or citizen's experience of transport - whether they are a direct user or a service, receive good from freight operators, or live in communities which are bounded by and regulated by transport provision.

The focus of the UK, and other countries is on the passenger experience - from planning to arrival at the final destination. This provides opportunities for ergonomic interventions to ensure that all stages of the journey are accessible to all users, and that transitions to other modes of transport occur smoothly.

Using the H-S model to guide research demands that attention is placed on all factors which might affect interaction with vehicles, systems and services. 
It may be argued that such a model can integrate existing research and show the many factors that might influence the undertaking and manner in which journeys takes place.

Designers can draw on a vast body of work in the form of real world surveys and interviews with drivers, operators and passengers through simulator studies and virtual CAD, and on to psychological studies of drivers, to help them create safe, usable and effective means of transport for future generations.

\section{References}

[1] J. Wilson, Methods in the understanding of human factors, Chapter 1 in Wilson, J. and Corlett, N., (eds) Evaluation of Human Work, $3^{\text {rd }}$ Edition Taylor and Francis, 2005

[2] R. Benedyk, A. Woodcock, A. and A. Harder, The HexagonSpindle Model for Educational Ergonomics, Work, (2008), 32, $3,237-248$

[3] A.Woodcock, A. Woolner, and R. Benedyk, Applying the Hexagon-Spindle Model for Educational Ergonomics to the design of school environments for children with autistic spectrum disorders, Work, (2008), 32, 3, 249-260,

[4] D. Basacik, The effect of obesity on access to and usability of public and private transport modalities, TRL Report UPR $\mathrm{T} / 143 / 07,2007$

[5] Lopez, R.P., Neighbourhood risk factors for obesity, Obesity, (2007), 15,8, 211-219

[6] D.R. Bassett, J. Pucher, R. Buehler, D.L. Thompson and S.E.Crouter, Walking, cycling, and obesity rates in Europe, North America and Australia, Journal of Physical Activity and Health, (2008), 5, 795-814.

[7] J. Garrard, Active Transport; Children and Young People, VicHealth, available http://www.chpcp.org/resources/Active transport children an d young people FINAL.pdf accessed on 13/2/2011,2009

[8] R. Kircz, Fat tax not to be introduced because of logistics says Ryanair, UKMEDIXNEWS http://www.ukmedix.com/weightloss/fat tax not to be intro duced because of logistics say ryanair4655.cfm, Accessed 27/2/2011,2009

[9] R.Anderson, The Back Pain of Bus Drivers, Prevalence in an Urban Area of California. Spine, (1991), 17, 12, pp. 14811488.

[10] L.Peacock, Overweight bus drivers told to lose weight or be re-deployed, PersonnelToday, (2009), 3 September.

[11] R.Niles, Bigger riders mean bigger headaches for theme parks, Theme Park Insider http://www.themeparkinsider.com/flume/200710/510/ accessed 13/2/11, 2007

[12] Anon, Ambulances retrofitted to cater for the obese, NursingTimes. Net, http://www.nursingtimes.net/nursingpractice/clinical-specialisms/accident-andemergency/ambulances-refitted-to-cater-forobese/5025067.article. accessed 13/2/11,2011

[13]A.Woodcock and S.Topalovic, The Stratford E-bus park and ride evaluation, Transport and User Experience Conference, Coventry University, March $4^{\text {th }}, 2011$.

[14] P.Ulleberg, Social influence from the back-seat: factors related to adolescent passengers' willingness to address unsafe drivers. Transportation Research Part F, 7, 17-3,2004
[15] J.T.Shope and C.R.Bingham, . Teen Driving: Motor-vehicle crashes and factors that contribute. American Journal of Preventive Medicine, (2008), 35

[16] M.Haglund and L.Aberg, Speed choice in relation to speed limit and influences from other drivers, Transport Research Part F, Traffic Psychology and Behaviour, 3, 1, 39-51,2000

[17] L.Bethesda, M. Joint, and D. Connell,, Aggressive Driving. Three Case Studies, AAA Foundation for Traffic Safety, Washington DC.,1997

[18] H.Oinas-Kukkonen and M. Harjumaa, A systematic framework for designing and evaluating persuasive systems. In $\mathrm{H}$ Oinas-Kukkonen, P. F. V. Hasle, M. Harjumaa, K. Segerstahl, and P. Ohrstrom, editors, PERSUASIVE, volume 5033 of Lecture Notes in Computer Science, Springer, 164- 176., 2008

[19] G. Geiser, Man Machine Interaction in Vehicles. ATZ 87, p $74-77,1985$

[20] M. Tönnis, V. Broy andG. Klinker, A Survey of Challenges Related to the Design of 3D User Interfaces for Car Drivers. In Proceedings of the 1st IEEE Symposium on 3D User Interfaces (3D UI), March 2006.

[21] DIN Deutsches Institut für Normung Road vehicles Ergonomic aspects of transport information and control systems - Dialogue management principles and compliance procedures, Mar. 2003. Ref.No.: DIN EN ISO 15005:2003.

[22] A.Stevens, A. Quimby.A. Board, T. Kersloot, and P. Burns, Design guidelines for safety of in-vehicle information systems, Project report PA3721/01, TRL Limited, 2002

[23] D. Kern and A, Schmidt, Design space for driver based automotive user interfaces, Proceedings of the First International Conference on Automotive User Interfaces and Interactive Vehicular Applications (AutomotiveUI 2009), Sep 2122 2009, Essen, Germany, downloadable from http://www.pervasive.wiwi.uni-

due.de/uploads/tx itochairt3/publications/p3-kern.pdf. accessed 13/3/2011., 2009

[24]H. You, H. Oesterling, J. Bucciaglia, B. Lowe, B.Gilmore and A.Freivalds, Bus Operator Workstation Evaluation and Design Guidelines: Summary, TRANSPORTATION RESEARCH BOARD NATIONAL RESEARCH COUNCIL, NATIONAL ACADEMY PRESS, Washington, D.C. ,1997

[25] D.Shinar, M. Bourla, M and L. Kaufman, Synchronization of Traffic Signals as a Means of Reducing Red-Light Running, Human Factors, (2004), 46, 2, 367-372.

[26] C.W.Hulfine and D.D Adams, Safety benefits of signal coordination. Paper presented at the Institute of Transportation Engineers 65th Annual Conference, August,1995

[27] D. Shinar and R. Compton, Aggressive driving: An observation study of driver, vehicle, and situational variables. Accident Analysis and Prevention (2004), 36, 429-437.

[28]Department for Transport , The future of urban transport, Available from http://www.dft.gov.uk/pgr/regional/policy/urbantransport/ accessed 28/2/2011, 2009

[29] P. Barker and A. Woodcock, Driving skills and new technology, International Journal of Vehicle Design, (2011), (in press)

[30] D. Harris The influence of human factors on operational efficiency, Aircraft Engineering and Aerospace Technology (2006), 78, 1, 20-25

[31] S. Stewart, Crew utilisation: project: aircrew fatigue, scheduling and performance, paper presented at Association of Aerospace Medical Examiners Conference, Stafford, 9 April,2005

[32] C. Mayhew and M. Quinlan,, Economic pressure, multitiered subcontracting and occupational health and safety in 
Australian long-haul trucking, Employee Relations, (2006), $28,3,212-229$

[33] M. Belzer, Sweatshops on Wheels: Winners and Losers in Trucking Deregulation, Oxford University Press, Oxford, 2000
[34] J. Stoop and W. Thissen, Transport safety: trends and challenges from a systems perspective, Safety Science, (1997), $26,1 / 2,107-20$. 